\title{
The possible role of postprandial hyperglycaemia in the pathogenesis of diabetic complications
}

\author{
A. Ceriello \\ Chair of Internal Medicine, University of Udine, P. le S. Maria della Misericordia, Udine, Italy \\ Department of Pathology and Medicine, Experimental and Clinical, University of Udine, Udine, Italy
}

\begin{abstract}
It is both common and wise practice to adjust the treatment of diabetic patients to obtain plasma glucose concentrations as close as possible to the 'normal range', correcting both postprandial hyperglycaemic spikes and the less increased, but persistently high, plasma glucose concentration between meals. The 'Diabetes Control and Complications Trials (DCCT) and the United Kingdom Prospective Diabetes Study (UKPDS) have provided evidence that intensive treatment can prevent complications associated with diabetes mellitus. In both studies, effectiveness of hyperglycaemic treatment was assessed by means of the glycated haemoglobin level. This is an integrated measure of both postprandial and fasting hyperglycaemia. The absolute and relative importance of the two
\end{abstract}

conditions, however, could differ depending upon the organ or system suffering from diabetic complications and other more or less known individual factors. This paper aims to emphasize the effects of acute hyperglycaemia, in particular, postprandial hyperglycaemia, on the development of diabetic complications. The role of oxidative stress as a mediator of acute hyperglycaemia is further discussed. More investigation in this area is required so that treatment can be eventually individualised. Perhaps, in some patients, efforts could be concentrated on the control of hyperglycaemic spikes and/or specific organ or system susceptibility to either acute or chronic hyperglycaemia. [Diabetologia (2003) 46[Suppl1]:M9-M16]

Keywords Type 2 diabetes, plasma glucose, hyperglycaemia, oxidative stress, diabetic complications.
It is generally agreed that the ideal treatment of diabetic patients is the restoration of plasma glucose concentrations in the 'normal range'. In common medical practice this goal is elusive, as a result of practical difficulties and the risk of hypoglycaemia. Moreover, the clinical usefulness of optimising glycaemic control has long been suggested by logic rather than supported by evidence. Eventually, two large-scale prospective clinical trials, the Diabetes Control and Complica-

Received: 17 April 2001 / Revised: 27 August 2001

Published online: 7 November 2002

C) Springer-Verlag 2002

Corresponding author: A. Ceriello, Chair of Internal Medicine, University of Udine, P. le S. Maria della Misericordia, 33100 Udine, Italy, E-mail: antonio.ceriello@dpmsc.uniud.it Abbreviations: GFR, Glomerular filtration rate; ICAM-1, intercellular adhesion molecule-1. tions Trial (DCCT) [1] and the United Kingdom Prospective Diabetes Study (UKPDS) [2] definitely settled the question of the efficacy of intensive treatment in preventing diabetic complications.

These trials reported that the incidence of complications could be reduced by lowering glycated haemoglobin $\left(\mathrm{HbA}_{1 \mathrm{c}}\right)$, a measure of mean blood glucose concentrations [1, 2]. However, DCCT researchers suggested that "mean $\mathrm{HbA}_{1 \mathrm{c}}$ is not the most complete expression of the degree of hyperglycaemia. Other features of diabetic glucose control, which are not reflected by $\mathrm{HbA}_{1 \mathrm{c}}$, could add to or modify the risk of complications. For example, the risk of complications could be more highly dependent on the extent of postprandial glycaemic excursion." [3].

Chronic hyperglycaemia has been postulated to be a cause of microvascular $[1,2]$ and probably macrovascular [4], diabetic complications. However, a rapid 
increase in blood glucose concentrations, in particular in the postprandial phase, is a typical and frequent event in the life of diabetic patients. As a result, it is surprising how little emphasis researchers have previously put on postprandial glycaemic spikes as possible contributors to diabetic complications.

\section{Defining postprandial hyperglycaemia}

The word postprandial means after a meal: therefore, postprandial hyperglycaemia refers to plasma glucose concentrations after eating. Glucose concentrations begin to rise about $10 \mathrm{~min}$ after the start of a meal as a result of the absorption of dietary carbohydrates. The profile of postprandial hyperglycaemia is determined by many factors including the timing, quantity and composition of the meal, carbohydrate content and composition of the meal, insulin and glucagon secretion, etc. Because the absorption of food persists for 5 to $6 \mathrm{~h}$ after a meal in both diabetic and non-diabetic people, the optimal time to measure postprandial glucose is an open question. However, the American Diabetes Association has suggested that "in general, a measurement of plasma glucose $2 \mathrm{~h}$ after the start of a meal is practical, generally approximates the peak value in patients with diabetes, and provides a reasonable assessment of postprandial hyperglycaemia" [5].

This suggestion is supported by a recent observation that the level of glycaemia reached at $2 \mathrm{~h}$ after an OGTT is closely related to the level of glycaemia after a standardized meal (mixed meal in the form of wafers containing oat-fractionation products, soy protein, and canola oil sweetened with honey: $345 \mathrm{kcal}, 10.7 \mathrm{~g}$ fat, $12.1 \mathrm{~g}$ protein, $8.9 \mathrm{~g}$ simple sugars, $41.1 \mathrm{~g}$ starch, and $3.8 \mathrm{~g}$ dietary fibre) [6].

As reported above, in diabetes the postprandial phase is characterized by a rapid and large increase in blood glucose concentrations. While anticipating additional data from prospective studies, we do have information on the effects of an acute rise in glucose concentration, not only in in vitro and animal models, but also in healthy and diabetic humans. Moreover, in many of these reports, glycaemic variations are comparable to those encountered in the postprandial phase in diabetic patients. The following discussion highlights the relation between acute glycaemic variations and phenomena, known or suspected to be related to diabetic complications.

\section{Acute hyperglycaemia and microvascular complications}

High blood glucose concentrations contribute to the genesis of glomerular hyperfiltration [7], a phenomenon known to precede the occurrence of diabetic kidney disease [8]. An acute increase in blood glucose produces an increase in glomerular filtration rate
(GFR) in diabetic patients [7]. This causes a more severe change in patients with proteinuria than in patients with normoalbuminuria $[9,10]$, i.e. acute hyperglycaemia causes a greater effect in patients already affected by nephropathy. Of interest, the acute glucoseinduced increase in GFR has an extremely rapid onset and persists as long as hyperglycaemia [11]. In vitro, it has been shown that intermittent exposure of mesangial cells to high glucose concentrations is a greater stimulus for hyperproduction of collagen than chronic exposure [12]. The stimulation of mesangium to hyperproduce collagen is considered an important event in the pathogenesis of diabetic nephropathy [13].

These observations seem to be consistent with a study of 52 patients with Type 1 diabetes mellitus between 1965 and 1983, which showed a definite relation between the annual medians of postprandial glucose and the time interval between the onset of diabetes and the development of nephropathy [14]. Moreover, postprandial plasma glucose has been shown to be an important determinant of both onset and development of nephropathy in Type 2 diabetic patients [15].

An important pathogenetic factor in the occurrence and progression of diabetic retinopathy is hyperperfusion of the retinal circulation [16]. Additionally, studies have shown that hyperglycaemia plays a key role in increasing retinal perfusion [17]. Blood flow in the retinae of diabetic patients closely parallels plasma glucose concentrations $[18,19]$. The direct effects of hyperglycaemia on retinal circulation were confirmed by studies on animals, whereby the induction of hyperglycaemia uniformly caused an increase in retinal blood flow [20, 21]. Even in the case of retinopathy, an 8 -year prospective study has shown that postprandial hyperglycaemia could condition the development of such complications in Type 2 diabetic patients [15].

Hyperglycaemia is surely a determining factor in the occurrence of diabetic neuropathy. Numerous clinical studies have shown that improving the control of blood glucose concentrations can stop and/or improve manifestations typical of this pathology [22, 23, 24]. Hyperglycaemia acutely induced in Type 1 diabetes at onset, or in the case of rapid decompensation in chronic diabetic patients, causes an impairment of the motor and sensory nerve conduction velocity $[25,26]$. The direct role of hyperglycaemia in the impairment of nerve function has been confirmed in normal subjects undergoing acute hyperglycaemic clamp $[27,28]$. Acute hyperglycaemia, as it can lower the pain threshold in both animals [29] and diabetic patients [30], could have a role in the genesis of neuropathic pain which afflicts diabetic patients.

\section{Acute hyperglycaemia and macroangiopathic complications}

The pathogenic role of glucose in cardiovascular disease is increasingly apparent, as confirmed by epide- 
miological studies carried out both on diabetic and non-diabetic patients [4].

There is increasing evidence that the postprandial state is an important contributing factor to the development of atherosclerosis in non-diabetic subjects [31]. Epidemiological evidence linking total plasma triglycerides to CVD risk has been the subject of much debate. Data now suggest that triglycerides do represent an independent risk factor for CVD [32]. However, studies of the postprandial state showed the role of triglycerides for CVD [33, 34] and stroke [35] as an independent risk factor. Increased concentrations of plasma LDL are correlated with increased risk of developing atherosclerotic vascular disease [36]. However, at any given plasma concentration of LDL there is a great individual variability in the extent of atherosclerosis and the expression of clinical disease [37]. The oxidative modification of LDL is an important and possibly obligatory step in the pathogenesis of the atherosclerotic lesion [37]. Triglycerides transferred to LDL are more susceptible to lipase-mediated hydrolysis, so that LDL size is reduced [38]. These small and dense LDL are more prone to oxidation [38]. The postprandial LDL contain more triglycerides and LDL from healthy donors are more prone to oxidation in the postprandial state in comparison to the postabsorptive state [39]. The development of atherosclerosis, myocardial infarction, and sudden cardiac death is at least partly due to increased activity of the coagulation system. Several investigations have shown the role of thrombus formation in the pathogenesis of atherosclerosis and acute cardiovascular events [40]. It is well established that coagulation factor VII is independently associated with the risk of CVD [41]. Dietary studies in humans have established a connection between plasma concentrations of triglyceride and factor VII coagulant activity $[42,43]$. Small controlled studies have shown recently that factor VII is activated during absorptive lipemia in healthy human subjects and in patients with coronary heart disease [44, 45]. Postprandial hypertriglyceridemia has been found to precede the activation of coagulation factor VII, and the degree of factor VII activation is proportional to the increase in plasma triglycerides [46]. Since there is extensive evidence of important interactions between plasma lipoproteins and coagulation, including platelet aggregation and fibrinolysis [47], it seems reasonable that there could be an increased thrombotic tendency in the postprandial phase. In recent years, the recognition of the key role the endothelium plays in vascular pathophysiology has stimulated intensive research work [48]. Many alterations found in the postprandial state could involve the endothelium. It has been found that endothelial dysfunction is convincingly involved in the pathogenesis of hypertension [49], oxidized LDL reduce endothelium-dependent relaxation [50], and transient postprandial hypertriglyceridemia decreases vascular reactivity in healthy volunteers [51].
Most of the cardiovascular risk factors which are modified in the postprandial phase in non-diabetic subjects are altered in diabetes mellitus and are directly affected by an acute increase of glycaemia.

In non-obese Type 2 diabetic patients with moderate fasting hypertriglyceridaemia, the atherogenic lipoprotein profile is amplified in the postprandial state [52]. Triglycerides in diabetes are related to hyperglycaemia [53] and the control of postprandial glucose excursions reduces the postprandial triglyceride increase [54]. Low-density lipoprotein oxidation in diabetes is related to metabolic control [55], and it has been shown that LDL oxidation increases after meals [56, 57]; this directly relates to the degree of hyperglycaemia [57]. An acute increase in clotting factor VII has been described during induced hyperglycaemia in both diabetic and healthy subjects [58], while an enhancement of thrombin activity has been shown in the postprandial phase in Type 2 diabetic patients; this was proportional to the level of hyperglycaemia [59]. Furthermore, the synthesis of fibrinogen, a strong risk factor for cardiovascular disease in both diabetic and non-diabetic subjects [60], increases during food intake in diabetic patients [61].

Adhesion molecules regulate the interaction between endothelium and leukocytes [62]. They are involved in the process of atherogenesis. An increase in their expression on the endothelial surface causes increased adhesion of leukocytes, in particular, monocytes [63]. It is well-known that this is one of the first steps in the process which leads to the atheroma. Among the various pro-adhesive proteins, special concern was aroused by intercellular adhesion molecule-1 (ICAM-1). The soluble form of ICAM-1 accumulates in cells and can be rapidly expressed on their surface after various stimuli [62]. The circulating form of this molecule was increased in subjects with vascular disease [64], and diabetes mellitus with or without vascular disease [65]. As a result, it can be considered a marker of the activation of the atherogenic process [66]. Acute hyperglycaemia in both normal and diabetic subjects is a sufficient stimulus for the circulating concentration of ICAM-1 to increase, thus activating one of the first stages of the atherogenic process $[67,68]$.

Finally, evidence shows that acute hyperglycaemia could cause endothelial dysfunction $[69,70]$ and an increase of blood pressure in diabetic [71, 72] and healthy subjects [28]. Furthermore, a rapid decrease of flow-mediated vasodilation has been shown in the postprandial phase in Type 2 diabetic patients which correlated inversely with the magnitude of postprandial hyperglycaemia [73].

Indirect evidence of the unfavourable role of acute hyperglycaemia on cardiovascular disease is also available. Hyperglycaemia during an acute cardiovascular event is unfavourable from a prognostic point of view in case of both myocardial infarction [74] and 
stroke [75]. A worse prognosis has been shown for both cases in diabetic and non-diabetic subjects [74, 75]. With regard to infarction, a recent meta-analysis has shown a continuous correlation between glucose serum concentrations and severity of the prognosis even in non-diabetic subjects [76]. Furthermore, intensive insulin treatment during acute myocardial infarction reduces long-term mortality in diabetic patients [77]. In myocardial infarction, increased glucose concentrations were capable of inducing such electrophysiological alterations as to favour the occurrence of arrhythmias whose outcome could even be fatal [78]. This is consistent with the evidence that in normal subjects an acute increase of glycaemia produces a significant prolongation of QT [79].

These data suggest that the concomitant increase of glycaemia in postprandial condition can amplify in diabetic patients an increase of cardiovascular risk factors while producing by itself several functional alterations favouring cardiovascular disease.

\section{Possible pathogenetic mechanisms}

The studies quoted above show that a rapid glycaemic increase can alter the physiologic homeostasis of various organs and systems. The processes through which hyperglycaemia acts are probably non-enzymatic labile glycation [80] and production of free radicals [81]. It is also likely that both processes contribute to the generation of the anomalies observed in case of hyperglycaemia.

In labile glycation, glucose binding through a nonenzymatic bond with an amino acid forms a compound like a Schiff base [80]. This reaction is dependent on glucose concentration and it is reversible [80]. If the amino acid associated with the reaction is fundamental to the functionality of the molecule, its activity will be lowered. As the bond is reversible, protein activity is restored when glucose serum concentrations decrease [80]. There is experimental evidence of this process for many biological compounds [80].

Oxidative stress is a recognised pathogenic process of the complications of diabetes [82].

The production of free radicals from glucose can be obtained biochemically in three ways: (i) during labile glycation [83]; (ii) directly from glucose through a process of auto-oxidation [84]; (iii) through intracellular activation of the sorbitol pathway, which unbalances the NADH/NAD ${ }^{+}$system and favours the production of free radicals [85].

However, the most convincing evidence linking glucose and oxidative stress is the recent demonstration of the intracellular production of free radicals in conditions of hyperglycaemia. The endothelium was found to be freely permeable to glucose due to the receptor GLUT-1 [86]. As a result, the cell, having free glucose supply in connection with the circulating con-

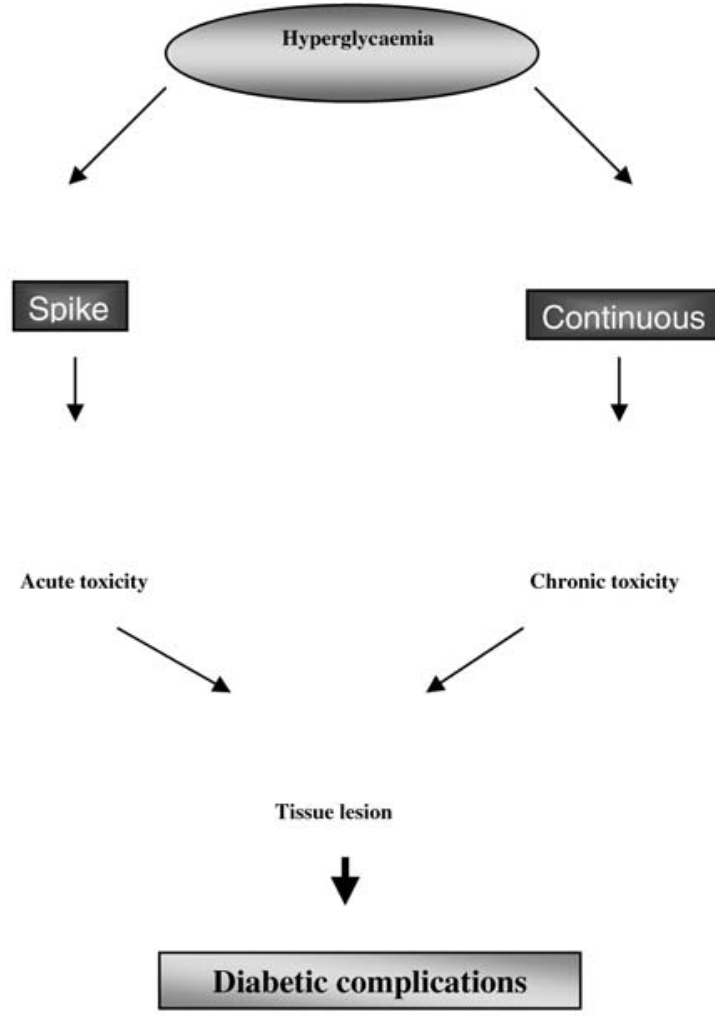

Fig. 1. Evidence suggests that the acute effects of glucose serum concentration can add to those produced by chronic hyperglycaemia, contributing to the final picture of complicated diabetes

centration, will transform it into energy. This implies that, at the mitochondrial level, the free glucose efflux is transformed not only into production of energy but also into unrestrained production of superoxide anions [86]. This elegant experiment shows that glucose can produce free radicals depending on concentration and it thus strengthens the hypothesis that an acute increase of glucose serum concentration can equally produce acute oxidative stress [86]. The evidence that in vivo superoxide anion plasma concentrations are increased in diabetic patients and correlate with the level of glycaemia, provides strong support to this hypothesis [87].

There is both indirect and direct evidence supporting the concept that, in vivo, acute hyperglycaemia works through the production of oxidative stress. Indirect evidence is obtained through the use of antioxidants which can hinder some of the effects acutely induced by hyperglycaemia such as endothelial dysfunction $[28,69,70,71]$, activation of coagulation [88] and increase of ICAM-1 in the plasma [67]. This suggests that the action of acute hyperglycaemia is mediated by the production of free radicals.

Direct evidence is also linked to an estimate of the effects of acute hyperglycaemia on oxidative stress markers. Numerous reports indicate that during an oral glucose challenge, a reduction of the antioxidant defences is observed [89, 90, 91]. This effect can be 

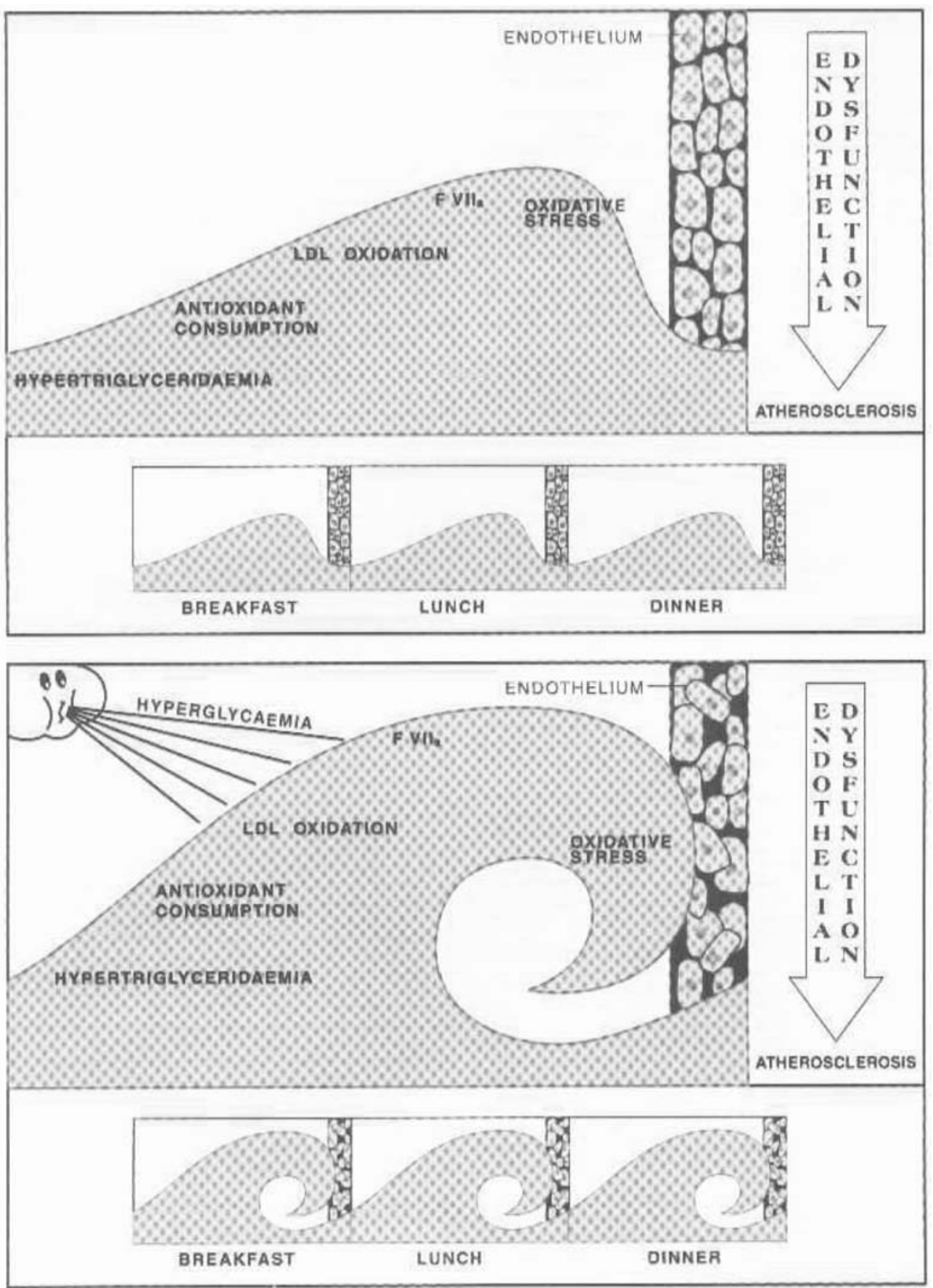

Fig. 2. The upper section illustrates the concept that several postprandial events combine to make waves that could eventually wear down the endothelial mole. The lower section represents the postulated effect of postprandial hyperglycaemia: like a strong wind, it causes billows that strike the wall and can rapidly tear it down. Reprinted with permission [31]

found even in more physiologic situations, for example, while eating a meal [92]. The role of hyperglycaemia can be highlighted by giving a patient two different meals. This will result in two different concentrations of postprandial hyperglycaemia; the greater drop in the antioxidant activity is linked with the higher concentrations of hyperglycaemia [57]. The evidence that in diabetic subjects LDLs are more prone to oxidation in the postprandial phase, matches these data [56]. Even in this situation higher concentrations of hyperglycaemia are matched with a greater oxidation of LDLs [57].

\section{Conclusions}

Hyperglycaemia can acutely induce alterations of normal human homeostasis. Of note, acute increases in serum glucose concentrations cause alterations in both normoglycaemic subjects and in diabetic subjects with 
basic hyperglycaemia. On the basis of this evidence it can be hypothesised that the acute effects of glucose concentrations can add to those produced by chronic hyperglycaemia, thus contributing to the final picture of complicated diabetes (Fig. 1).

A hypothetical sequence might be that, in the postprandial phase, oxidative stress is generated, with triglycerides playing an important role in this effect. Subsequently LDL oxidation, thrombosis activation and endothelial dysfunction occur, in a setting of meal-induced antioxidant consumption, and combine in favouring diabetic complications and possibly the occurrence of a cardiovascular event. In diabetes the simultaneous postprandial hyperglycaemic spike has the potential to amplify this phenomenon. This concept is allegorically summarised in Figure 2.

The precise relevance of postprandial hyperglycaemia to the development of diabetic complications is not currently comprehensive or quantifiable. There is a constant tendency for rapid variation of hyperglycaemia in diabetic patients, in particular in the postprandial phase. Thus, it can be hypothesised that it could exert an influence on the onset of complications. This theory is supported by the concept that there is no threshold for blood glucose concentrations in the development of diabetic complications. This was originally reported by the DCCT researchers in Type 1 diabetes with regard to microvascular disease [93]. The UKPDS expanded this evidence to Type 2 diabetic patients and macrovascular disease [94].

Prospective controlled studies on this topic have helped to clarify the importance of this phenomenon, implying a profound revision of the current therapeutic approach. It seems advisable to consider, from both a clinical and practical point of view, this new aspect of diabetes - the control of postprandial hyperglycaemic spikes - in the treatment of the disease.

\section{References}

1. The Diabetes Control and Complications Trials (DCCT) Research Group (1993) The effect of intensive treatment of diabetes on the development and progression of long-term complications in insulin-dependent diabetes mellitus. N Engl J Med 329:977-986

2. UKPDS (1998) Intensive blood glucose control with sulphonylureas or insulin compared with conventional treatment and risk of complications in patients with type 2 diabetes (UKPDS 33). UK Prospective Diabetes Study (UKPDS) Group. Lancet 352:837-853

3. The Diabetes Control and Complications Trial Research Group (1995) The relationship of glycemic exposure $\left(\mathrm{HbA}_{1 \mathrm{c}}\right)$ to the risk of development and progression of retinopathy in the Diabetes Control and Complicaions Trial. Diabetes 44:968-983

4. Laakso M (1999) Hyperglycemia and cardiovascular disease in type 2 diabetes. Diabetes 48:937-942

5. American Diabetes Association (2001) Postprandial blood glucose. Diabetes Care 24:775-778
6. Wolever TMS, Chiasson JL, Csima A et al. (1998) Variation of postprandial plasma glucose, palatability, and symptoms associated with a standardized mixed test meal versus 75 g oral glucose. Diabetes Care 21:336-340

7. Skott P, Vaag A, Hother-Nielsen O et al. (1991) Effects of hyperglycemia on kidney function, atrial natriuretic factor and plasma renin in patients with insulin-dependent diabetes mellitus. Scand J Clin Lab Invest 51:715-727

8. Wiseman MJ, Saunders AJ, Keen H, Viberti GC (1985) Effect of blood glucose control on increased glomerular filtration rate and kidney size in insulin-dependent diabetes. N Engl J Med 312:617-621

9. Tuttle KR, Bruton JL, Perusek MC, Lancaster JL, Kopp DT, De Fronzo RA (1991) Effect of strict glycemic control on renal haemodynamic response to aminoacids and renal enlargement in insulin-dependent diabetes mellitus. N Engl J Med 324:1626-1632

10. Remuzzi A, Viberti GC, Ruggenenti P, Battaglia C, Pagni R, Remuzzi G (1990) Glomerular response to hyperglycemia in human diabetic nephropathy. Am J Physiol 259:F545-F552

11. De Cosmo S, Earle K, Morocutti A et al. (1993) Glucoseinduced changes in renal haemodynamics in proteinuric Type I (insulin-dependent) diabetic patients: inhibition by acetylsalicilic acid infusion. Diabetologia 36:622-627

12. Takeuchi A, Throckmorton DC, Brogden AP, Yoshizawa N, Rasmussen H, Kashgarian M (1995) Periodic high extracellular glucose enhances production of collagens III and IV by mesangial cells. Am J Physiol 268:F13-F19

13. Steffes MW, Bilous RW, Sutherland DER, Mauer SM (1992) Cell and matrix components of the glomerular mesangium in type I diabetes. Diabetes 41:679-684

14. Hasslacher C, Ritz E (1987) Effect of control of diabetes mellitus on progression of renal failure. Kidney Int 32 [Suppl 22]:53-56

15. Schchiri M, Kishikawa H, Ohkubo Y, Wake N (2000) Long-term results of the Kumamoto Study on optimal diabetes control in type 2 diabetic patients. Diabetes Care 23 [Suppl 2]:B21-B29

16. Kohner EM, Patel V, Rassam SMB (1995) Role of blood flow and impaired autoregulation in the pathogenesis of diabetic retinopaty. Diabetes 44:603-607

17. Grunwald JE, Bruckner AJ, Schwartz SS et al. (1990) Diabetic glycemic control and retinal blood flow. Diabetes 39:602-607

18. Patel V, Rassam SMB, Chen HC, Kohner EM (1994) Oxygen reactivity in diabetes mellitus: effect of hypertension and hyperglycemia. Clin Sci (Colch) 86:689-695

19. Rassam SMB, Patel V, Kohner EM (1995) The effect of experimental hypertension on retinal autoregulation in humans: a mechanism for the progression of diabetic retinopathy. Exp Physiol 80:53-68

20. Atherton A, Hill DW, Keen H, Young S, Edwards EJ (1980) The effect of acute hyperglycemia on the retinal circulation of the normal cat. Diabetologia 18:233-237

21. Sullivan PM, Davies EG, Caldwell G, Morris AH, Kohner EM (1990) Retinal blood flow during hyperglycemia. Invest Ophthalmol Vis Sci 31:2041-2045

22. Pirart J (1978) Diabetes mellitus and its degenerative complications: a prospective study of 4,400 patients observed between 1947 and 1973. Diabetes Care 1:139-140

23. Young RJ, Macintyre CA, Martin CN et al. (1986) Progression of subclinical neuropathy in young patients with Type I (insulin-dependent) diabetes: associated with glycemic control and microangiopathy (microvascular complications). Diabetologia 29:156-161 
24. Masaoka S, Lev-Ran A, Hill LR, Vakil G, Hon EHG (1985) Heart rate variability in diabetes: relationship to age and duration of the disease. Diabetes Care 8:64-68

25. Ward JD, Fisher DJ, Barnes CG, Jesop JD (1971) Improvement in nerve conduction following treatment in newly diagnosed diabetics. Lancet i:428-430

26. Gregersen G (1968) Variations in motor conduction velocity produced by acute changes of the metabolic state in diabetic patients. Diabetologia 4:273-277

27. Yeap BB, Russo A, Fraser RJ, Wittert GA, Horowitz M (1996) Hyperglycemia affects cardiovascular autonomic nerve function in normal subjects. Diabetes Care 19:880-882

28. Marfella R, Verrazzo G, Acampora R et al. (1995) Glutathione reverses systemic hemodynamic changes by acute hyperglycemia in healthy subjects. Am J Physiol 268:E1167E1173

29. Lee JH, McCarty R (1990) Glycemic control of pain threshold in diabetic and control rats. Physiol Behav 47:225-230

30. Thye-Ronn P, Sindrup SH, Arendt-Nielsen L, Brennum J, Hother-Nielsen O, Beck-Nielsen H (1994) Effect of shortterm hyperglycemia per se on nociceptive and non-nociceptive thresholds. Pain 56:43-49

31. Ceriello A (2000) The postprandial state and cardiovascular disease: relevance to diabetes mellitus. Diabetes Metab Res Rev 16:125-132

32. Castelli WP (1986) The triglyceride issue: a view from Framingham. Am Heart J 112:432-437

33. Groot PHE, van Stiphuit WAHJ, Krauss XH et al. (1991) Post-prandial lipoprotein metabolism in normolipidemic men with and without coronary artery disease. Arterioscler Thromb 11:653-662

34. Patsch JR, Hopferwieser T, Miesenboeck G et al. (1992) The relationship of triglyceride metabolism and coronary artery disease: studies in the postprandial state. Arterioscler Thromb 12:1336-1345

35. Ruy JE, Howard G, Craven TE, Bond MG, Hagaman AP, Crouse JR (1992) Postprandial triglyceridemia and carotid atherosclerosis in middleaged subjects. Stroke 23:823-828

36. Castelli WP, Garrison RJ, Wilson PWF, Abbott RD, Kalousdian S, Kannel WB (1986) Incidence of coronary heart disease and lipoprotein cholesterol levels: The Framingham Study. JAMA 256:2835-2838

37. Witztum JL (1994) The oxidation hypothesis of atherosclerosis. Lancet 344:793-795

38. McKeone BJ, Patsch JR, Pownal HJ (1993) Plasma triglycerides determine low density lipoprotein composition, physical properties and cell specific binding. J Clin Invest 91:1926-1933

39. Lechleitner M, Hoppichler F, Föger B, Patsch JR (1994) Low-density lipoproteins of postprandial state induce cellular cholesteryl ester accumulation in macrophages. Arterioscler Thromb 14:1799-1807

40. Falk E (1985) Unstable angina with fatal outcome: dynamic coronary thrombosis leading to infarction and/or sudden death: autopsy evidence of recurrent mural thrombosis with peripheral embolization culminating in total vascular occlusion. Circulation 71:699-708

41. Junker R, Heinrich J, Schulte H, Loo J van de, Assmann G (1997) Coagulation factor VII and the risk of coronary heart disease in healthy men. Arterioscler Thromb 17:1539-1544

42. Marcman P, Sandström B, Jespersen J (1990) Effects of total fat content and fatty acid composition in diet on factor VII coagulant activity and blood lipids. Atherosclerosis 80:227-233
43. Connelly JB, Roderick PJ, Cooper JA, Meade TW, Miller GJ (1993) Positive association between self-reported fatty food consumption and factor VII coagulant activity, a risk factor for coronary heart disease, in 4246 middle-aged men. Thromb Haemost 70:250-252

44. Miller GJ, Martin JC, Mitropoulos KA et al. (1991) Plasma factor VII is activated by postprandial triglyceridemia, irrespective of dietary fat composition. Atherosclerosis 86:163-171

45. Silveira A, Karpe F, Blombäck M, Steiner G, Waldius G, Hamsten A (1994) Activation of coagulation factor VII during alimentary lipemia. Arterioscler Thromb 14:60-69

46. Silveira A, Karpe F, Johnsson H, Bauer KA, Hamsten A (1996) In vivo demonstration in humans that large postprandial triglyceride-rich lipoproteins activate coagulation factor VII through the intrinsic coagulation pathway. Arterioscler Thromb 16:1333-1339

47. Gasser JA, Betteridge DJ (1990) Lipids and thrombosis. Baillière's Clin Endocrinol Metab 4:923-938

48. Furchgott RF, Zawadzki JV (1980) The obligatory role of the endothelial cells in the relaxation of arterial smooth muscle by acetylcholine. Nature 288:373-376

49. Panza JA, Quyyumy A, Brush JE, Epstein SE (1990) Abnormal endothelium dependent vascular relaxation in patients with essential hypertension. $\mathrm{N}$ Engl J Med 323:22-27

50. Chin JH, Azhar S, Hoffman BB (1992) Inactivation of endothelium-derived relaxing factor by oxidized lipoproteins. J Clin Invest 89:10-18

51. Lundman P, Eriksson M, Schenck-Gustafsson K, Karpe F, Tornvall P (1997) Transient triglyceridemia decreases vascular reactivity in young, healthy men without risk factors for coronary heart disease. Circulation 96:3266-3268

52. Cavallero E, Dachet C, Neufcou D, Wirquin E, Mathe D, Jacotot B (1994) Postprandial amplification of lipoprotein abnormalities in controlled type II diabetic subjects: relationship to postprandial lipemia and C-peptide/glucagon levels. Metabolism 43:270-278

53. Howard BV (1987) Lipoprotein metabolism in diabetes mellitus. J Lipid Res 28:613-628

54. Hanefeld M, Fischer S, Schulze J et al. (1991) Therapeutic potentials of Acarbose as first-line drug in NIDDM insufficiently treated with diet alone. Diabetes Care 14:732737

55. Tsai EC, Hirsch IB, Brunzell JD, Chait A (1994) Reduced plasma peroxyl radical trapping capacity and increased susceptibility of LDL to oxidation in poorly controlled IDDM. Diabetes 43:1010-1014

56. Diwadkar VA, Anderson JW, Bridges SR, Gowri MS, Oelgten PR (1999) Postprandial low density lipoproteins in type 2 diabetes are oxidized more extensively than fasting diabetes and control samples. Proc Soc Exp Biol Med 222:178-184

57. Ceriello A, Bortolotti N, Motz E et al. (1999) Mealinduced oxidative stress and low-density lipoprotein (LDL) oxidation in diabetes: the possible role of hyperglycemia. Metabolism 48:1503-1508

58. Ceriello A, Giugliano D, Quatraro A, Dello Russo P, Torella R (1988) Blood glucose may condition factor VII levels in diabetic and normal subjects. Diabetologia 31:889-891

59. Ceriello A, Taboga C, Tonutti L et al. (1996) Post-meal coagulation activation in diabetes mellitus: the effect of Acarbose. Diabetologia 39:469-473

60. Ceriello A (1997) Fibrinogen and diabetes mellitus. Is it time for intervention trials ? Diabetologia 40:731-734 
61. Bruttomesso D, Iori E, Kiwanuka E et al. (2001) Insulin infusion normalizes fasting and post-prandial albumin and fibrinogen synthesis in type 1 diabetes mellitus. Diabet Med 18:915-920

62. Ruosladti E (1991) Integrins. J Clin Invest 187:1-5

63. Lopes-Virella MF, Virella G (1992) Immune mechanism of atherosclerosis in diabetes mellitus. Diabetes 41 [Suppl 2]:86-91

64. Blann AD, McCollum CN (1994) Circulating endothelial cell/leukocyte adhesion molecules in atherosclerosis. Thromb Haemost 72:151-154

65. Ceriello A, Falleti E, Bortolotti N et al. (1996) Increased circulating ICAM-1 levels in Type-2 diabetic patients: the possible role of metabolic control and oxidative stress. Metabolism 45:498-501

66. Gearing AJH, Newman W (1993) Circulating adhesion molecules in disease. Immunol Today 14:506-512

67. Ceriello A, Falleti E, Motz E et al. (1998) Hyperglycemiainduced circulating ICAM-1 increase in diabetes mellitus: the possible role of oxidative stress. Horm Metab Res 30:146-149

68. Marfella R, Esposito K, Giunta R et al. (2000) Circulating adhesion molecules in humans: role of hyperglycemia and hyperinsulinemia. Circulation 101:2247-2251

69. Giugliano D, Marfella R, Coppola L et al. (1997) Vascular effects of acute hyperglycemia in humans are reversed by L-arginine. Evidence for reduced availability of nitric oxide during hyperglycemia. Circulation 95:1783-1790

70. Title LM, Cummings PM, Giddens K, Nassar BA (2000) Oral glucose loading acutely attenuates endothelium-dependent vasodilation in healthy adults without diabetes: a effect prevented by vitamin $\mathrm{C}$ and E. J Am Coll Cardiol 36:2185-2191

71. Ceriello A, Motz E, Cavarape A et al. (1997) Hyperglycemia counterbalances the anti-hypertensive effect of glutathione in diabetic patients. Evidence linking hypertension and glycemia through the oxidative stress in diabetes mellitus. J Diabet Complic 11:250-255

72. Marfella R, Nappo F, De Angelis L, Paolisso G, Tagliamonte MR, Giugliano D (2000) Hemodynamic effects of acute hyperglycemia in type 2 diabetic patients. Diabetes Care 23:658-663

73. Shige H, Ishikawa T, Suzukawa M et al. (1999) Endothelium-dependent flow-mediated vasodilation in the postprandial state in type 2 diabetes mellitus. Am J Cardiol 84:1272-1274

74. Bellodi G, Manicardi V, Malavasi V et al. (1989) Hyperglycemia and prognosis of acute myocardial infarction in patients without diabetes mellitus. Am J Cardiol 64:885888

75. Gray CS, Taylor R, French JM et al. (1987) The prognostic value of stress hyperglycaemia and previosly unrecognized diabetes in acute stroke. Diabet Med 4:237-240

76. Capes SE, Hunt D, Malmberg K, Gerstein HC (2000) Stress hyperglycaemia and increased risk of death after myocardial infarction in patients with and without diabetes: a systematic overview. Lancet 355:773-778

77. Malmberg K, Norhammar A, Wedel H, Ryden L (1999) Glycometabolic state at admission: important risk marker of mortality in conventionally treated patients with diabetes mellitus and acute myocardial infarction. Long-term results from the diabetes and insulin-glucose infusion in acute myocardial infarction (DIGAMI) study. Circulation 99:26262632

78. Gokhroo R, Mittal SR (1989) Electrocardiographic correlates of hyperglycemia in acute myocardial infarction. Int J Cardiol 22:267-269

79. Marfella R, Nappo F, De Angelis L, Siniscalchi M, Rossi F, Giugliano D (2000) The effect of acute hyperglycaemia on QTc duration in healthy man. Diabetologia 43:571-575

80. Ceriello A, Quatraro A, Giugliano D (1992) New insights on non-enzymatic glycosylation may lead to therapeutic approaches for the prevention of diabetic complications. Diabet Med 9:297-299

81. Ceriello A (1997) Acute hyperglycaemia and oxidative stress generation. Diabet Med 14:S45-S49

82. Giugliano D, Ceriello A, Paolisso G (1996) Oxidative stress and diabetic vascular complications. Diabetes Care 19:257-267

83. Mullarkey CJ, Edelstein D, Brownlee M (1990) Free radical generation by early glycation products: a mechanism for accelerated atherogenesis in diabetes. Biochem Biophys Res Commun 173:932-939

84. Wolff SP, Dean RT (1987) Glucose auto-oxidation and protein modification. The potential role of "autoxidative glycosylation" in diabetes. Biochem J 245:243-250

85. Williamson JR, Chang K, Frangos M et al. (1993) Hyperglycemic pseudohypoxia and diabetic complications. Diabetes 42:801-813

86. Nishikawa T, Edelstein D, Du X-L et al. (2000) Normalizing mitochondrial superoxide production blocks three pathways of hyperglycemic damage. Nature 404:787-790

87. Ceriello A, Giugliano D, Quatraro A, Dello Russo P, Lefebvre PJ (1991) Metabolic control may influence the increased superoxide anion generation in diabetic serum. Diabet Med 8:540-542

88. Ceriello A, Giacomello R, Stel G et al. (1995) Hyperglycemia-induced thrombin formation in diabetes. The possible role of the oxidative stress. Diabetes 44:924-928

89. Ceriello A, Bortolotti N, Crescentini A et al. (1998) Antioxidant defenses are reduced during oral glucose tolerance test in normal and non-insulin dependent diabetic subjects. Eur J Clin Invest 28:329-333

90. Tessier D, Khalil A, Fulop T (1999) Effects of an oral glucose challenge on free radicals/antioxidants balance in an older population with type II diabetes. J Gerontol 54:541-545

91. Konukoglu D, Hatemi H, Ozer EM, Gonen S, Akcay T (1997) The erythrocyte glutathione levels during oral glucose tolerance test. J Endocrinol Invest 20:471-475

92. Ceriello A, Bortolotti N, Motz E et al. (1998) Meal-generated oxidative stress in type 2 diabetic patients. Diabetes Care 21:1529-1533

93. DCCT (1996) The absence of a glycemic threshold for the development of long-term complications: the perspective of the Diabetes Control and Complications Trial. Diabetes 45:1289-1298

94. Stratton IM, Adler AI, Neil HAW et al. (2000) Association of glycaemia with macrovascular and microvascular complications of type 2 diabetes (UKPDS 35): prospective observational study. BMJ 321:405-412 